\title{
A liquid fraction of extracellular matrix inhibits glioma cell viability in vitro and in vivo
}

\author{
Mark H. Murdock ${ }^{1,2}$, George S. Hussey ${ }^{1,2}$, Jordan T. Chang ${ }^{2}$, Ryan C. Hill ${ }^{3}$, David G. \\ Nascari ${ }^{1,2}$, Aparna V. Rao ${ }^{5}$, Kirk C. Hansen ${ }^{3}$, Lesley M. Foley ${ }^{4}$, T. Kevin Hitchens ${ }^{4,5}$, \\ Nduka M. Amankulor ${ }^{6}$ and Stephen F. Badylak ${ }^{1,2}$ \\ ${ }^{1}$ Department of Surgery, University of Pittsburgh, Pittsburgh, PA, USA \\ ${ }^{2}$ McGowan Institute for Regenerative Medicine, University of Pittsburgh, Pittsburgh, PA, USA \\ ${ }^{3}$ Department of Biochemistry and Molecular Genetics, University of Colorado Denver, Aurora, CO, USA \\ ${ }^{4}$ Animal Imaging Center, School of Medicine, University of Pittsburgh, Pittsburgh, PA, USA \\ ${ }^{5}$ Department of Neurobiology, University of Pittsburgh, Pittsburgh, PA, USA \\ ${ }^{6}$ Department of Neurological Surgery, University of Pittsburgh, Pittsburgh, PA, USA \\ Correspondence to: Stephen F. Badylak, email: badylaks@upmc.edu \\ Keywords: extracellular matrix; brain cancer; glioma treatment; dynamic reciprocity; tissue organization field theory \\ Received: September 14, $2021 \quad$ Accepted: February 07, $2022 \quad$ Published: February 21, 2022
}

Copyright: @ 2022 Murdock et al. This is an open access article distributed under the terms of the Creative Commons Attribution License (CC BY 3.0), which permits unrestricted use, distribution, and reproduction in any medium, provided the original author and source are credited.

\section{ABSTRACT}

Suppressive effects of extracellular matrix (ECM) upon various cancers have been reported. Glioblastoma multiforme has poor prognosis and new therapies are desired. This work investigated the effects of a saline-soluble fraction of urinary bladder ECM (ECM-SF) upon glioma cells. Viability at 24 hours in 1, 5, or $10 \mathrm{mg} / \mathrm{mL}$ ECM-SF-spiked media was evaluated in primary glioma cells $(0319,1015,1119)$, glioma cell lines (A172, T98G, U87MG, C6), and brain cell lines (HCN-2, HMC3). Viability universally decreased at 5 and $10 \mathrm{mg} / \mathrm{mL}$ with U87MG, HCN-2, and HCM3 being least sensitive. Apoptosis in 0319 and 1119 cells was confirmed via NucView 488. Bi-weekly intravenous injection of ECM-SF $(120 \mathrm{mg} / \mathrm{kg})$ for 10 weeks in Sprague-Dawley rats did not affect weight, temperature, complete blood count, or multi-organ histology $(N=5$ ). Intratumoral injection of ECM-SF ( $10 \mathrm{uL}$ of $30 \mathrm{mg} /$ $\mathrm{mL}$ ) at weeks 2-4 post $\mathrm{C} 6$ inoculation in Wistar rats increased median survival from 24.5 to 51 days (hazard ratio for death 0.22 ) and decreased average tumor volume at time of death from $349 \mathrm{~mm}^{3}$ to $90 \mathrm{~mm}^{3}$ over 10 weeks $(N=6)$. Mass spectrometry identified 2,562 protein species in ECM-SF, parent ECM, and originating tissue. These results demonstrate the suppressive effects of ECM on glioma and warrant further study.

\section{INTRODUCTION}

The extracellular matrix (ECM) represents a major portion of the tissue microenvironment and is composed of functional and structural molecules such as cytokines, growth factors, proteoglycans, collagens, and matrix-bound nanovesicles, among others [1-3]. The microenvironment markedly influences cell behavior, survival, gene expression, and phenotype and is a major factor in the dynamic and continuous cell-matrix crosstalk referred to as "dynamic reciprocity" $[4,5]$.
The tissue organization field theory (TOFT) supposes that metaplastic and neoplastic transformation of cells is directly related to changes in the microenvironment/ECM $[6,7]$. Therefore, if this theory is accurate, manipulation of the tumor microenvironment could modulate neoplastic cell behavior or survival. The specific components of the ECM milieu that modulate cell phenotype are only partially understood.

Several studies have documented the effects of mammalian non-neoplastic ECM upon neoplastic cells in vitro and in vivo. These studies have included several 
types of cancer including breast, urinary bladder, prostate, colon, skin, and esophageal, among others [8-15]. A recent study showed the beneficial therapeutic effects of an ECM hydrogel derived from normal esophageal tissues upon dysplastic esophageal mucosa (i.e. Barrett's esophagus) in which metaplastic cells regressed to a squamous epithelial phenotype in a canine model [16]. Importantly, a study by the same group found increased apoptosis in one metaplastic and two neoplastic cell lines exposed to urinary ladder matrix ECM [13].

The objective of the present study was to determine the in vitro and in vivo effects of a saline-soluble fraction of ECM harvested from non-neoplastic porcine urinary bladder (ECM-SF) upon glioblastoma cells. ECM from porcine urinary bladder is FDA approved for many clinical applications related to wound healing and due to the source material's ease of acquisition and simple decellularization process it is a common research material in many laboratories. The isolation of ECM from native porcine bladder involves a selective reduction in composition and elimination of cellular debris. The further processing of ECM to ECM-SF represents an enrichment of saline-soluble species, excluding saline-insoluble macromolecules. Utilizing saline-soluble fraction allowed ECM-SF to be injected into a glioma tumor without resection, thereby allowing alteration instead of removal of the tumor microenvironment. A secondary objective of the present study was to compare the proteomic composition of the native bladder, ECM, and ECM-SF as a first step toward identifying potential molecules of interest.

It was hypothesized that introducing ECM-SF into the tumor microenvironment would have the potential to modulate the glioma cell phenotype and thereby prolong survival or reduce tumor volume in an animal model of glioblastoma. We further hypothesized that ECM-SF would contain a distinct proteomic composition from that of the parent ECM.

\section{RESULTS}

\section{Saline-soluble fraction of ECM decreased glioma cell viability}

Porcine urinary bladder was decellularized into ECM and then lyophilized, comminuted, tumbled in saline, centrifuged, filtered, and concentrated 200-fold by volume into ECM-SF (Figure 1A). ECM-SF was clear and colorless with viscosity comparable to water and protein content of approximately $25-30 \mathrm{mg} / \mathrm{mL}$ as measured by A280 absorbance. At $1 \mathrm{mg} / \mathrm{mL}$ cell groups averaged deadto-live ratios between 0.9 - to 2.0 -fold that of the media control (Figure 1B). At $5 \mathrm{mg} / \mathrm{mL}$ cell groups averaged ratios between 10 - to 23 -fold, and at $10 \mathrm{mg} / \mathrm{mL}$ cell groups averaged ratios between 15 - and 37-fold compared to the media control. ANOVA indicated no differences within the 1 $\mathrm{mg} / \mathrm{mL}$ treatment group $(P=0.13)$ whereas at $5 \mathrm{mg} / \mathrm{mL}$ the 1119 and $\mathrm{A} 172$ dead-to-live ratios were significantly higher than that of $\mathrm{U} 87 \mathrm{MG}(P<0.01)$. At $10 \mathrm{mg} / \mathrm{mL}$ the 1015 and 1119 ratios were significantly higher than that of U87MG and the A172 dead-to-live ratio was significantly higher than those of non-neoplastic HCN-2 and HMC3 $(P<0.01)$.

\section{ECM-SF induced apoptosis in glioma cells}

Time-lapse video showed non-neoplastic HMC3 cells emitting virtually no fluorescence over 12 hours in media
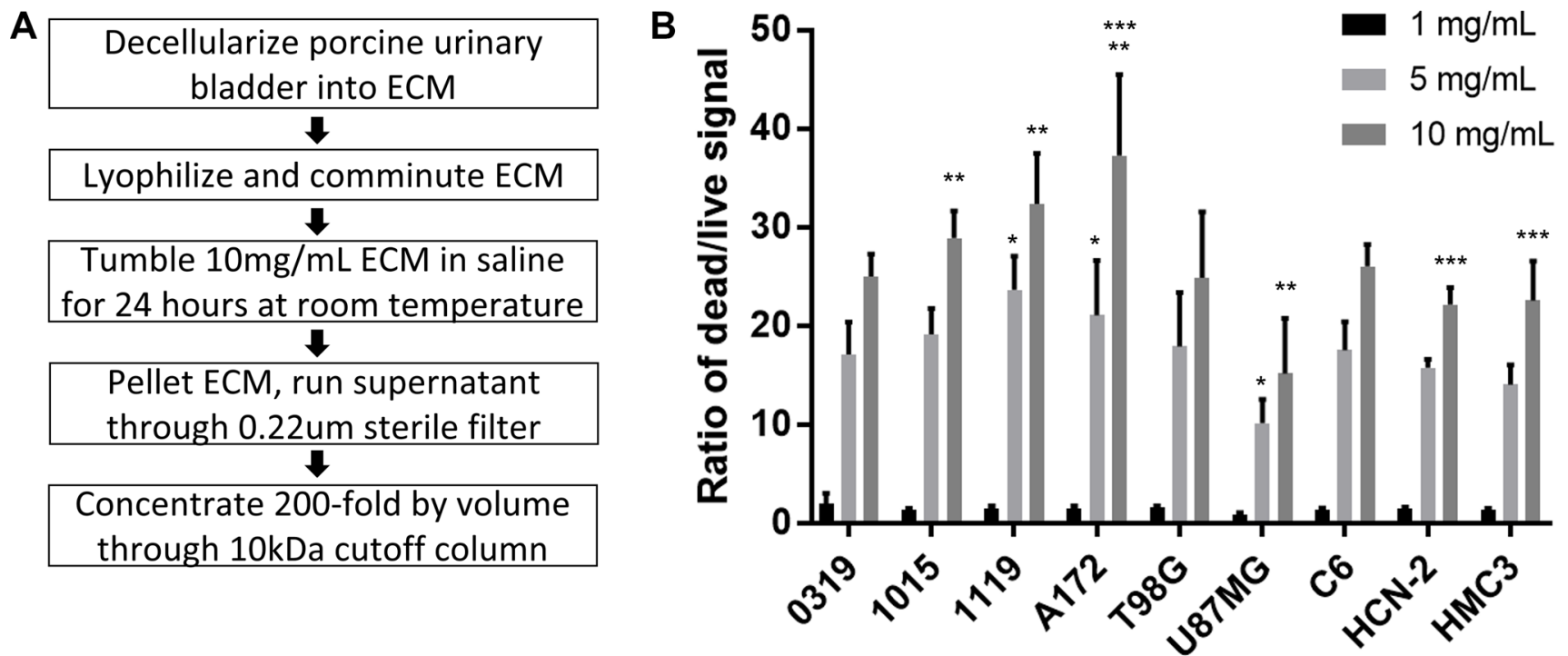

Figure 1: ECM-SF isolation and effect on glioma cells. Procedure for isolating and concentrating a saline-soluble fraction of ECM derived from porcine bladder (A). ANOVA with post hoc Tukey's Honest Significant Difference show no difference at $1 \mathrm{mg} / \mathrm{mL}(P=0.13)$,

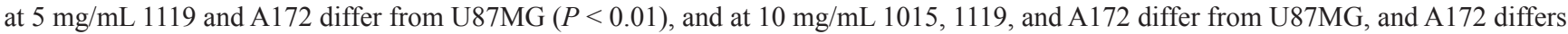
from HCN-2 and HMC3 $(P<0.01)(\mathbf{B})$. 
spiked with $3 \mathrm{mg} / \mathrm{mL}$ ECM-SF and $1.5 \mathrm{uM}$ NucView 488, a reagent fluorescent upon cleavage by active caspase-3 (Figure 2A, Supplementary Video 1). 1119 and 0319 cells, however, showed increasing amounts of nuclear fluorescence throughout the 12-hour period with 0319 cells showing an appreciably higher amount of fluorescence (Figure 2B and 2C, Supplementary Videos 2 and 3).

\section{Systemically injected ECM-SF did not alter hematology metrics}

There were no significant differences in weight $(P=$ $0.8)$ or temperature $(P=0.18)$ between the ECM-SF and saline-treated groups (Figure 3A, 3B). The ECM-SF group did gain more weight per animal on average (15.6 grams) than the saline group (4.6 grams), but the difference was not significant $(P=0.08)$. Hematology metrics for the two groups were normal with respect to red blood cell count (Figure 3C, $P=0.46$ ), red blood cell distribution (Figure 3D, $P=0.20$ ), hematocrit (Figure 3E, $P=0.32$ ), and hemoglobin levels (Figure 3F, $P=0.30$ ). H\&E staining of lung, spleen, liver, heart, brain, and kidney appeared normal for both groups.

\section{Brain tissue tolerated ECM-SF which was likely retained up to $24 \mathrm{~h}$}

H\&E staining showed no mononuclear cellular infiltration in response to the direct intracranial injection at
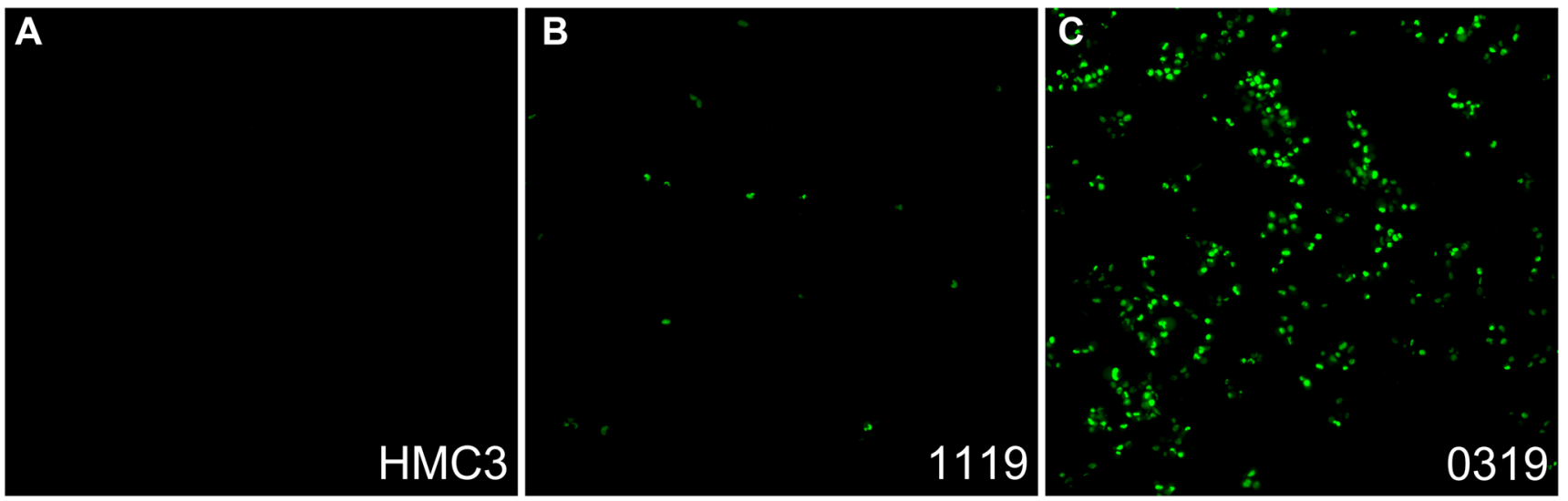

Figure 2: Caspase activity of glioma cells in ECM-SF spiked media. After 12 hours in media containing $3 \mathrm{mg} / \mathrm{mL}$ ECM-SF and $1.5 \mathrm{uM}$ NucView there is no fluorescence from HMC3 cells (A), some presence of nuclear fluorescence from 1119 cells (B), and a high presence of nuclear fluorescence from 0319 cells (C). Static data shown in graphical form is at the 12-hour timepoint.
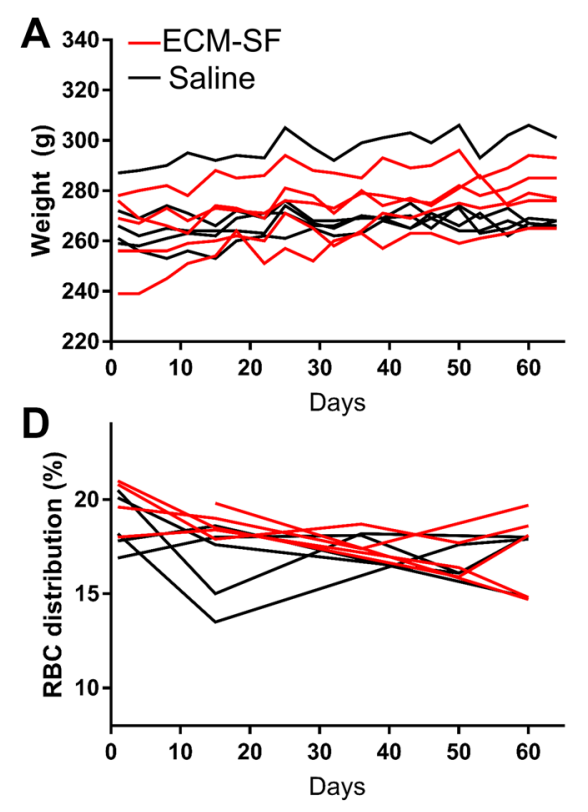

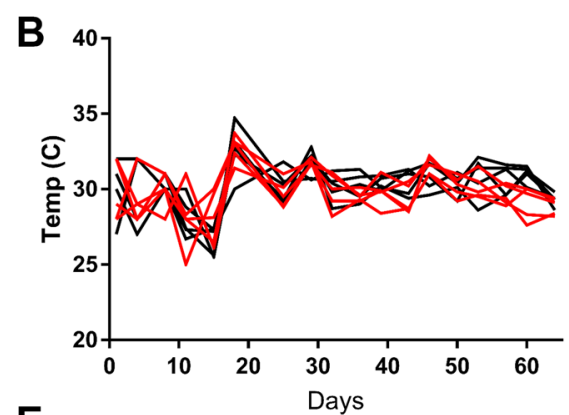

E

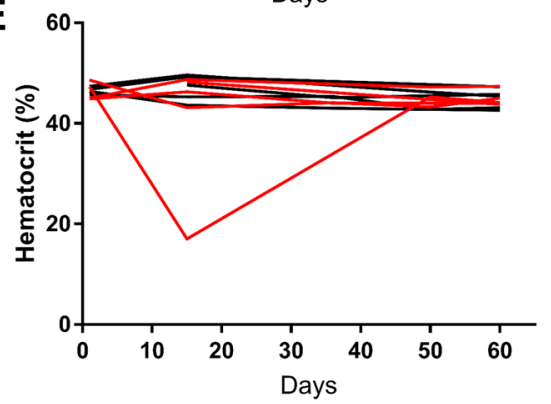

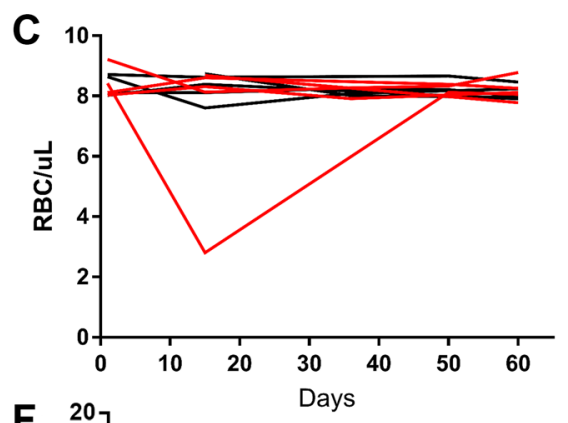

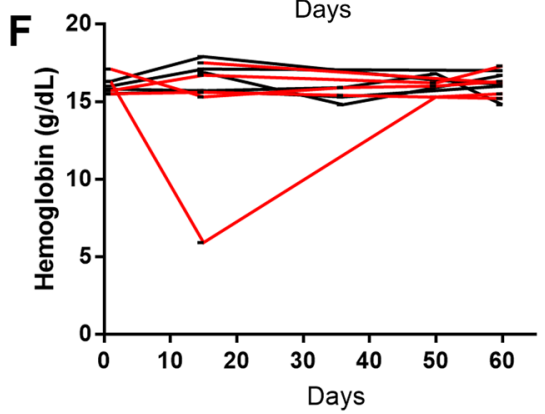

Figure 3: Systemic response to ECM-SF injections. No differences were found in weight (A) or temperature (B) between the ECM$\mathrm{SF}$ and saline-treated groups. Hematology metrics for the two groups were normal with respect to red blood cell count (C), red blood cell distribution (D), hematocrit (E), and hemoglobin levels (F). 
30 minutes (Figure 4A-A") or 24 hours (Figure 4B-B"). FITC traces approximating injection diffusion and location were clearly visible in the injection area at both timepoints (Figure 4C and 4D). The FITC signal at 30 minutes occupied approximately 22 times more area than at 24 hours (20,903 vs. 958 pixels) and displayed a gradually fading periphery compared to the sharply disappearing edge of the 24-hour signal.

\section{ECM-SF increased lifespan in glioblastoma model which correlated with lower tumor volume}

C6 cells were injected at day 0 and ECM-SF or saline injections were given intratumorally at days 7, 14, and 21 (Figure 5A). Of the six saline-treated animals, three died at days 18, 21, and 30, and three were sacrificed at days 24, 25, and 30 in accordance with IACUC tumor burden guidelines. Three ECM-SF treated animals were taken off protocol at days 22, 24, and 32. The three remaining ECM-SF treated animals survived until day
70 and presented as bright, alert, and responsive before electively being taken off protocol. ECM-SF increased median survival from 24.5 to 51 days and the hazard ratio for death was 0.22 (95\% CI, 0.05 to 0.97$)$. Survival curves were compared using both the Gehan-BreslowWilcoxon, which places more weight on early time points, and the Mantel-Cox method, which gives equal weight to all timepoints, resulting in $P=0.086$ and $P=0.046$, respectively (Figure 5B). The saline-treated rats had an average tumor volume of $349 \mathrm{~mm}^{3}$ at time of death compared to $90 \mathrm{~mm}^{3}$ for the ECM-SF treated animals. Unpaired $t$-test analysis showed significant differences between the tumor volumes of the two groups (Figure $5 \mathrm{C}, P=0.0057)$. The three ECM-SF treated rats that survived to day 70 had decreasing tumor volumes over time (Figure 5C). Representative MRI images show tumor characteristics over time (Figure 5D-5F). The six saline-treated animals that died by day 30 had large solid tumors which grew rapidly (Figure 5D). The three ECMSF treated animals which died by day 32 had smaller, slower growing tumors (Figure 5E). The three ECM-SF

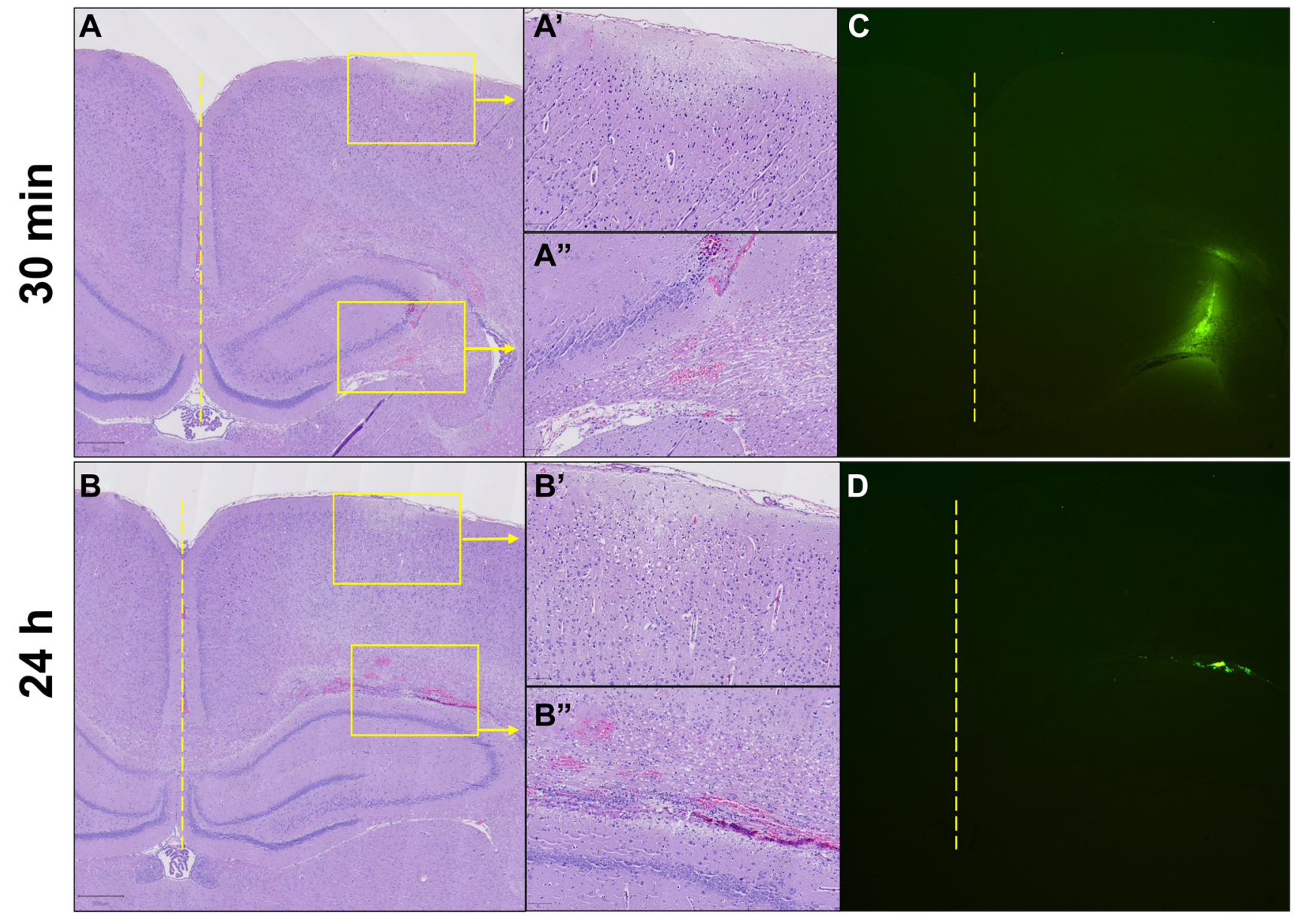

Figure 4: Acute intracranial cellular response to ECM-SF and retention of FITC-dextran-spiked ECM-SF after direct intracranial injection. No cellular infiltration was observed in response to the injection at 30 minutes $(\mathbf{A}-\mathbf{A}$ ”, $2 \times$ and $10 \times)$ or 24 hours (B-B”, $2 \times$ and 10×). FITC signal approximating injection diffusion and location at 30 minutes occupied $\sim 22$ times more area than at 24 hours and displayed a gradually fading periphery compared to the sharply disappearing edge of the 24-hour signal. (C, D). Yellow dotted line indicates the midline of the brain, yellow boxes indicate magnified areas. 
treated animals which survived to day 70 had smaller, slower growing tumors which resolved into a necrotic core (approximately $1.7 \mathrm{~mm}^{3}$ ) by day 70 (Figure 5F).

\section{ECM-SF has a distinct composition compared to parent ECM/tissue}

Native porcine bladder, decellularized ECM, and saline-soluble ECM-SF were subjected to global and targeted mass spectrometry analysis. A total of 2,562 distinct protein species $(N=3$ biological and technical replicates) were identified. Of these proteins, bladder contained 2,373 protein species, ECM contained 2,010 species, and ECM-SF contained 1,017 species. Proteins were sorted into functional categories (Figure 6A) or core matrisome proteins only (Figure 6B). All proteins and core matrisome proteins from bladder, ECM, and ECMSF were shown to be members of distinct compositional groups via principal component analysis (Figure 6C, 6D). Bladder biological replicates were shown to have the least amount of variability. Hierarchical clustering of all proteins showed biological replicates within each source material to be most related to each other, and ECM and ECM-SF were more closely related to each other than to the native bladder (Figure 6E, 6F). There were, however, many instances of differential presence of certain proteins between the biological replicates in each source material. ANOVA analysis identified the top fifty core ECM proteins showing a difference between the source materials (Figure 6F).

\section{ECM-SF enriches 618 proteins from parent ECM}

A volcano plot comparing the ECM-SF to ECM proteome showed 618 proteins enriched in the ECM-SF above a 2 -fold change and below a $P$ value of 0.1 .528 proteins present in the urinary bladder extracellular matrix (UB-ECM) were identified with the same inclusion criteria (Figure 7A). In the core matrisome, ECM-SF contained five proteins above a 2 -fold change and below a $P$ value of 0.1 compared to ECM, while ECM contained 51 proteins (Figure 7B, Supplementary Table 1).

\section{DISCUSSION}

The results of the present study show that a salinesoluble fraction of ECM can decrease glioma cell viability in vitro via caspase- 3 mediated apoptosis, and intratumoral injection intervention can decrease glioma tumor volume in vivo, correlating with longer survival. ECM-SF did not elicit an acute (24 hours) cellular response in rat
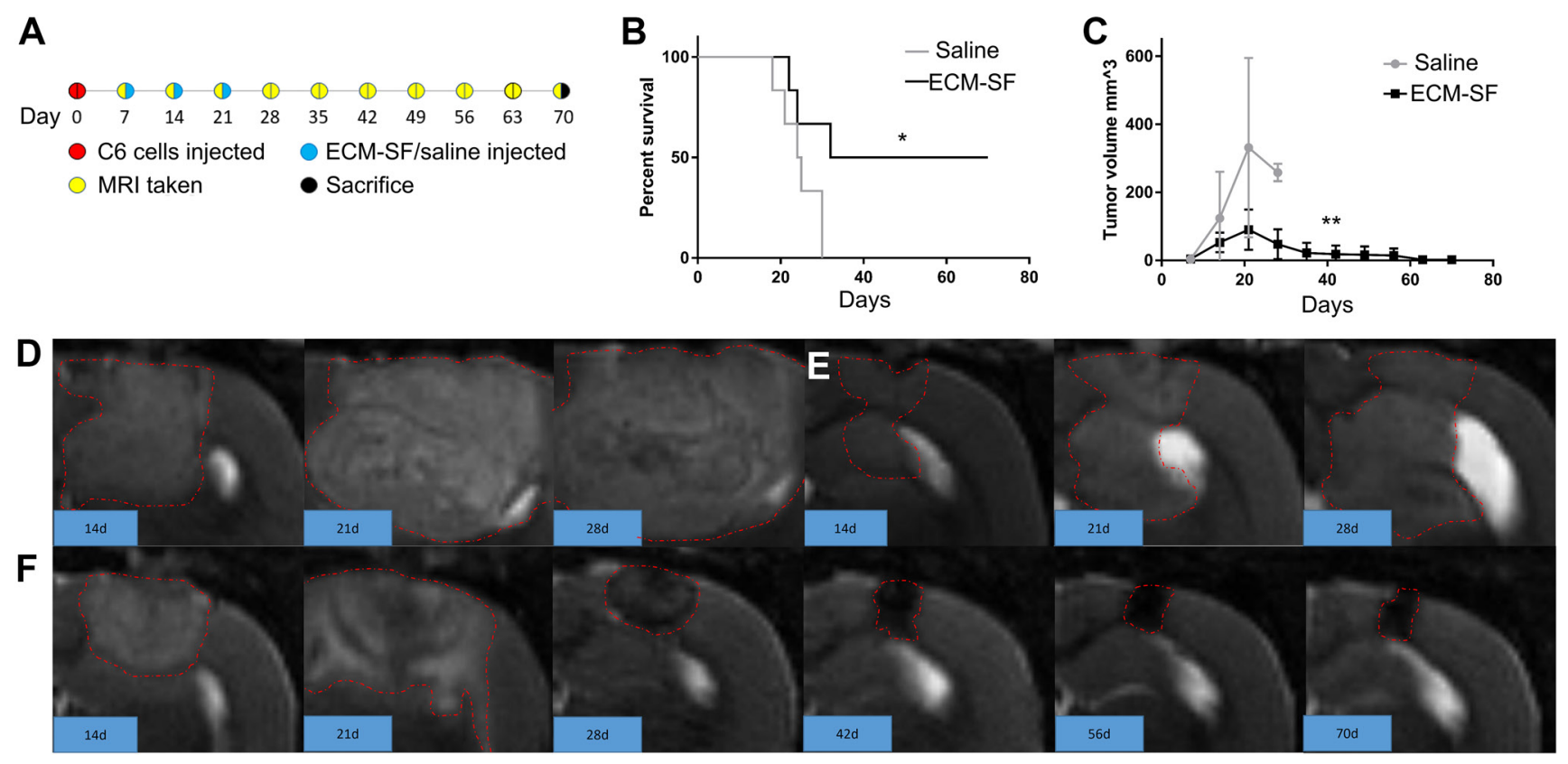

Figure 5: Pre-clinical model of treatment of glioblastoma with ECM-SF. (A) The 70-day experimental outline including inoculation of Wistar rats with C6 cells, three weekly injections of ECM-SF or saline, and weekly MRI scans until day 70. (B) The survival curves of ECM-SF vs. saline-treated animals $(N=6)$. Curve comparison with the Gehan-Breslow-Wilcoxon method shows no significant difference $(P=0.086)$ whereas the Mantel-Cox method shows significance $(P=0.046)$. $(\mathbf{C})$ The average tumor volumes of ECM-SF vs. saline-treated animals over 70 days. Error bars indicate standard deviation. Comparison with unpaired $t$ test shows significance $(P=$ 0.0057). Representative MRI images of primary tumor at days 14, 21, and 28 of (D) a saline-treated rat and (E) an ECM-SF treated rat that died in week 4, as well as weekly images through day 70 of an ECM-SF treated rat that was electively sacrificed at day 70 . (F) Tumor appears to have resolved into a small necrotic core with no recurrence of tumor mass. Tumor border outlined in a red dotted line. 

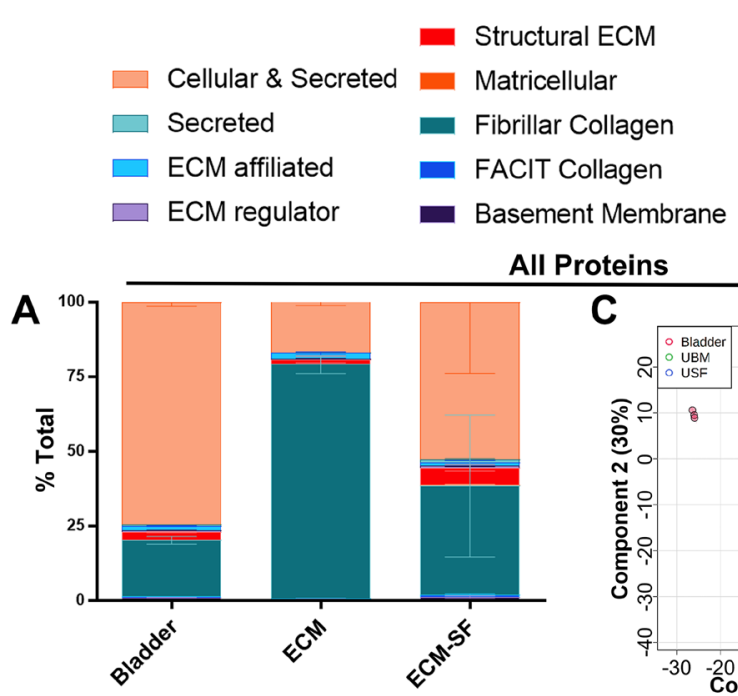

All Proteins
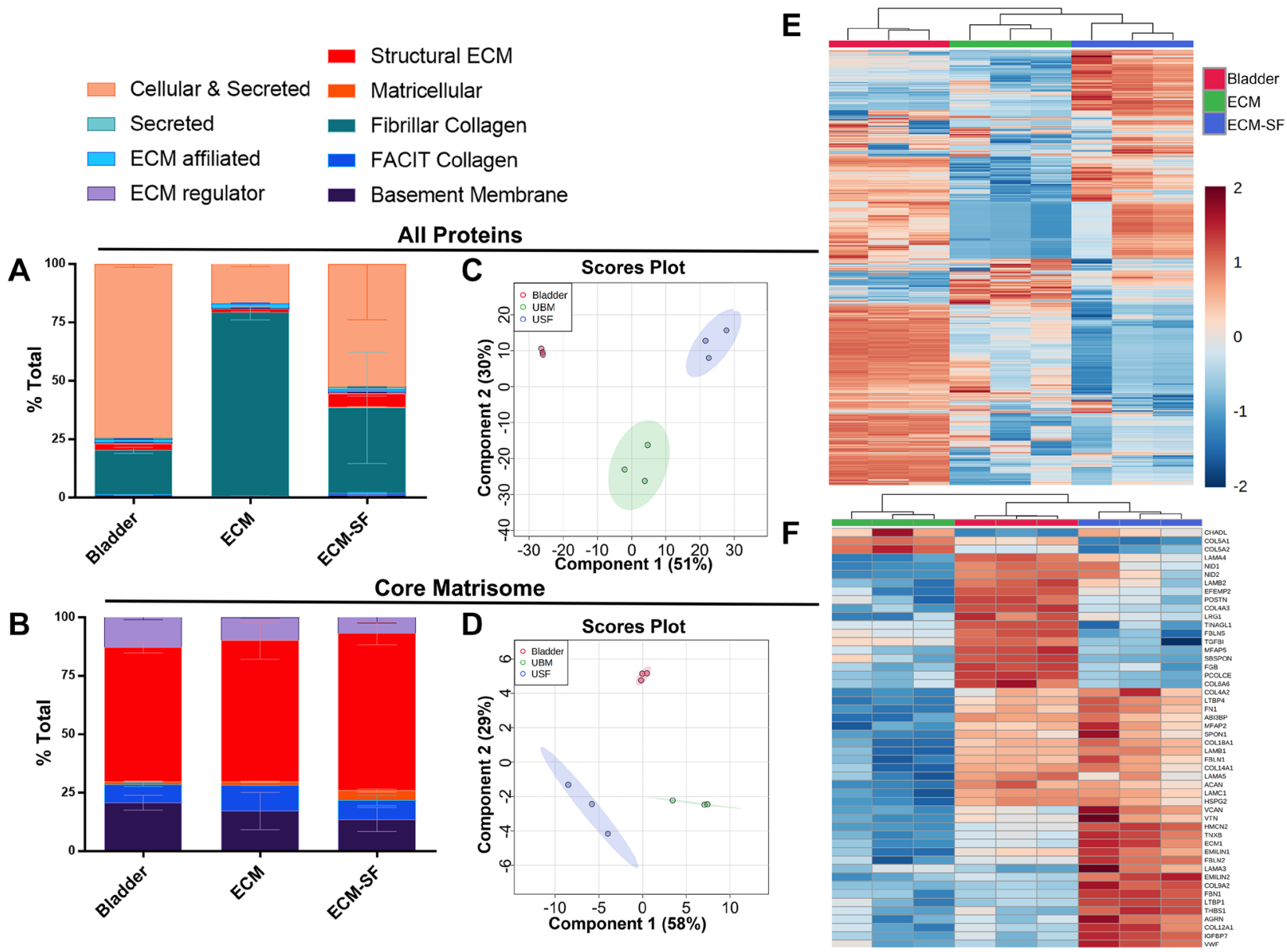

Figure 6: Global and targeted proteomic analysis of bladder, ECM, and ECM-SF. Sorting by functional categories reveals the majority to be Cellular \& Secreted, or Fibrillar Collagen (A). Each source material contains a similar core matrisome composition (B). Principal component analysis shows all proteins and core matrisome proteins from source materials to be distinct compositional groups $(\mathbf{C}$, D). 2,562 distinct protein species were identified: 2,373 in bladder, 2,010 in ECM, and 1,017 in ECM-SF (E). The top fifty differentially expressed core matrisome proteins from each source material were identified $(\mathbf{F})$.

A

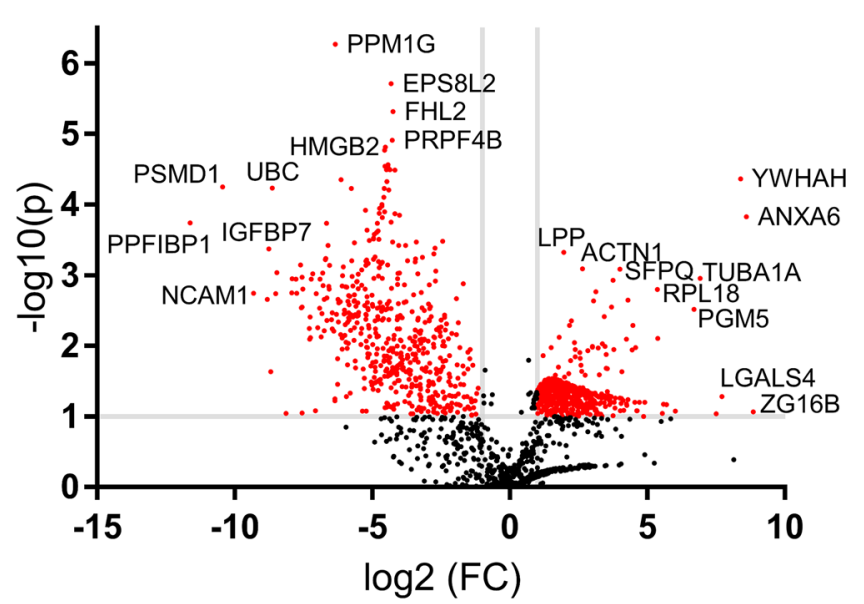

B

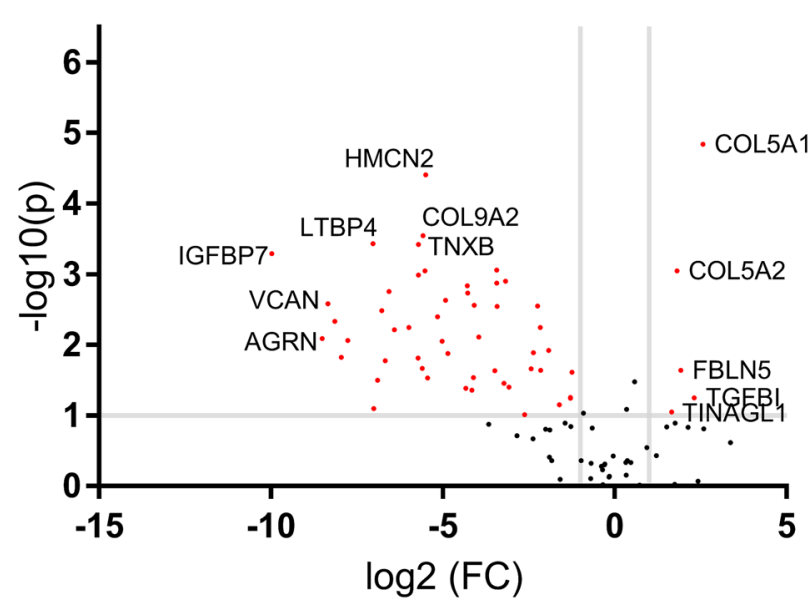

Figure 7: Volcano plot of ECM-SF compared to ECM. (A) 618 protein species were enriched two-fold or more in the ECM-SF while 528 protein species remained two-fold or higher in the parent ECM. (B) For the core matrisome, five protein species were enriched in the ECM-SF while 51 protein species remained two-fold or higher in the parent ECM. 
brain tissue, nor have deleterious effects on weight gain, temperature, or hematology metrics when administered intravenously (10 weeks). The protein profile of ECMSF was distinct from both its parent ECM and the source tissue. Several protein species (COL5A1, COL5A2, FBLN5, TGFBI, TINAGL1) were enriched in the salinesolubilization process. The results support the findings of other ECM-based studies and the TOFT; that is, that nonneoplastic mammalian ECM contains bioactive cues that can antagonize cancer cells and their in vivo progression $[10-14,16]$. The findings were present in vitro in both primary glioma cells and glioma cell lines, though with differing sensitivities. These findings led to anti-tumor results in the widely used allogeneic rat glioma model C6Wistar.

The concept that ECM and resident cells influence each other through an ongoing, bidirectional crosstalk is called "dynamic reciprocity" $[4,5]$. This dynamic process is seen in the tumor microenvironment wherein cancer cells slowly degrade, secrete, and remodel the local ECM which, in turn, can influence the gene expression of non-neoplastic cells to behave more cancer-like [8]. The opposite phenomenon also holds true; that is, that cancer cells introduced into non-neoplastic microenvironments can transform to become less cancer-like. Bissel et al. showed that breast cancer cells respond to their microenvironment and can revert from their malignant phenotype [8]. Hodde et al. found that porcine small intestinal submucosa ECM (SIS-ECM) did not hasten the formation of primary tumors and decreased the volume of recurring tumors after surgical resection [9]. Hurst et al. found that high grade metastatic bladder cancer cells grown on SIS-ECM hydrogel decreased invasion and showed more organized growth than when grown on Matrigel or collagen [10]. Saldin et al. showed that UB-ECM and esophagus-derived ECM both decreased proliferation of esophageal cancer cells and that UB-ECM differentially increased apoptosis [13]. Wolf et al. showed that a solid UB-ECM scaffold inhibited melanoma tumor formation in a macrophage-dependent manner in mice [14]. These findings are consistent with the concept of tissue organization field theory which challenges the dogma of somatic mutation theory regarding the origin of cancer $[6,7]$. Somatic mutation theory is cell-centric, attributing the rise of cancer solely to the accumulation of DNA damage and mutation in cells. In contrast, TOFT is tissue-centric, ascribing the onset of cancer to aberrations in the microenvironment, of which the ECM is a major part. These concepts are not mutually exclusive. If a microenvironment can induce oncogenesis, perhaps an alternative microenvironment can modulate oncogenic behavior, or simply eradicate the affected cells. This concept begets a potential alternative approach to conventional cancer therapeutics. While the literature largely describes the transformative effect of ECM on cancer cells, the main result seen in this work is glioma cell death. This result is in line with the observations of Saldin et al. where UB-ECM increased apoptosis in esophageal cancer cells and might be due to the increased concentration of ECM components found in ECM-SF after the 200 -fold reduction in volume.

Porcine urinary bladder was the source tissue for the ECM used in the present study for several reasons. It is one of the most readily available and commonly used ECM biomaterials. The decellularization process to manufacture UB-ECM is well established, relatively simple, and involves primarily mechanical removal of the tunica serosa, tunica muscularis externa, tunica submucosa, and most of the tunica muscularis mucosa to decrease cellularity [17]. Harsh decellularization processes that rely upon chemical detergents tend to deplete growth factors, and these detergents often remain in the resulting bioscaffold, skewing experimental results. ECM biomaterials derived from porcine urinary bladder are commercially available (MatriStem, ACell, Columbia, Maryland), retain bioactivity after electron beam terminal sterilization, and have been used in a clinical trial involving esophageal adenocarcinoma patients wherein the implanted bioscaffold degraded within two weeks, promoting functional remodeling of the esophagi which have remained cancer-free to date (clinicaltrials.gov Identifier: NCT02396745).

ECM is a complex structure comprised of hundreds of molecules of various size. Fractionation is a reductionist approach toward identifying molecules of interest. ECM is most commonly used therapeutically as a solid sheet, a comminuted powder, or as a hydrogel. Slivka et al. showed that UB-ECM hydrogel can be centrifuged into "structural" and "soluble" fractions, which have differential effects in regulating macrophage behavior [18]. Several advantages derive from working with a "liquid-form ECM". A liquid form allows for the ECM components to be concentrated tens or hundreds of times, which is not possible with sheets, powders, or digested hydrogels. The liquid form allows for intratumoral injection without first resecting any tissue mass which may have future application in treatment of surgically inoperable tumors. Extraction of UB-ECM using normal saline is logical due to its physiological relevance (interstitial fluid also having $0.9 \% \mathrm{NaCl}$ ). It is known that implanted solid forms of ECM and hydrogel formulations can recruit stem/progenitor cells and modulate macrophage responses within 24 hours. Therefore, this length of time for the saline-extraction may capture many of the molecules responsible for these functional observations $[19,20]$. It is believed that host degradation of implanted ECM is essential for the release of bioactive components which account for positive remodeling effects [21, 22].

It is not surprising that ECM-SF did not elicit an acute cellular response in the rat brain. UB-ECM hydrogels have been used intracranially for stroke studies without ill effect and indeed have exhibited positive tissue remodeling within the central nervous system [19, 23]. Studies have also shown UB-ECM hydrogels to recruit 
doublecortin-positive neural progenitor cells, support neuron viability, and stimulate axon growth [24-27]. SISECM (Durasis, Cook Biotech, West Lafayette, Indiana) has been used as a dural substitute where it is claimed to remodel into native tissue. Other ECM-based materials made from pericardium or dermis are also commercially available [28]. Intravenous injection was conducted to determine the safety of this ECM formulation and allowed for future potential investigation of a systemic approach for cancer, whether prophylactic or therapeutic. Future studies will address the mechanism by which the body processes and metabolizes ECM components, the salient species that are permeable through the blood-brain-barrier, the effect upon the immune system, and toxicological studies of specific molecules.

Although the molecular mechanism(s) by which ECM-SF mitigates cancer cell growth is beyond the scope of the present study, the proteomic analysis conducted herein does shed light on possible protein effector molecules. Of the 2,562 protein species identified in the native bladder, ECM, and ECM-SF, 1,017 were contained in the ECM-SF. The volcano plot showed ECM-SF contained only five proteins enriched more than two-fold from the parent ECM which combined have a mixed effect on glioma. The expression levels of COL5A1 and COL5A2 are significantly correlated with glioma progression stage [29]. FBLN5 is downregulated in stage III and IV glioma and has been shown to inhibit glioma cell proliferation and invasion [30]. High TGFBI expression promotes proliferation and migration of glioma cells [31]. TINAGL1 is largely unstudied in the context of glioma but suppresses triple-negative breast cancer progression and metastasis [32]. Although these proteins were highlighted by the volcano plot, their role in driving the observed effects is unknown.

It is possible, and seems likely, that in addition to the direct anti-glioma effects of ECM-SF observed in vitro there are indirect anti-glioma effects attained through modulation of the immune system. It seems unlikely that the ECM-SF could exert direct anti-glioma effects in the C6-Wistar model throughout ten weeks when ECMSF injections only occurred on days 7,14 , and 21 . It is known that non-neoplastic ECM modulates macrophages away from an M1 activation state toward an M2-like state. Tumor associated macrophages, known as TAMs and perhaps better thought of as M(tumor activated), create an immunosuppressive microenvironment and secrete cytokines that activate anti-apoptotic programs in cancer cells [33]. Microenvironmental conditioning provided by ECM-SF may modulate TAMs away from their tumorsupportive role toward an M(ECM activated) state and allowing anti-tumor efficacy. This mechanism would explain the observation of gradually diminishing tumor mass.

There are limitations beyond those already mentioned with the present study. While the glioma cells included both primary cells and cell lines, the non-glioma cells used (HCN2 and HMC3) represent transformed immortalized cells that may not be representative of the cell population in patients. Culturing cells on $2 \mathrm{D}$ tissue culture plastic with growth media containing BSA has limitations and introduces variables, but this approach represented proof of concept that evolved into and justified an in vivo pilot study. While NucView 488 is marketed as a caspase- 3 specific substrate, it is based on a DEVD sequence which means it can also be cleaved by caspase-7. However, both caspase- 3 and 7 are classified as executioner caspases, direct precursors to apoptosis [34]. The non-neoplastic cell lines showed significant cell death at the $10 \mathrm{mg} / \mathrm{mL}$ of ECM-SF indicating higher concentrations need not be tested in vitro. While ECM materials have traditionally been reported to have excellent biocompatibility, it seems ECM-SF contains one or more highly concentrated components that can damage non-neoplastic cells if administered in sufficient amounts. These components may or may not be the same that elicit the anti-cancer effect so attempting to remove them may or may not be a useful strategy in future studies. If solid or hydrogel ECM could be concentrated to the same degree as ECM-SF, similar cytotoxic results would likely be observed as virtually all test articles become cytotoxic at sufficiently high concentrations. The FITC signal attached to $70 \mathrm{kda}$ dextran did not specifically track the diffusion and retention of any particular component within the ECM-SF and was meant to provide a limited approximation of the level of diffusion at early time points and where to search for a cellular response to the ECM-SF. The core matrisome of ECM-SF contained components as small as Von Willebrand factor $(500-20,000 \mathrm{kDa})$ and as large as versican (protein core of $360 \mathrm{kDa}$ ), supporting speculation that some of the ECM-SF components were also retained up to 24 hours. This is supported by previous work showing that ECM components from hydrogels injected into stroke cavities in rat brains were retained at 24 hours and up to at least 12 weeks [24, 25, 35]. The spatial diffusion observed in the FITC signal after 24 hours provided the rationale for using $30 \mathrm{mg} / \mathrm{mL}$ ECM$\mathrm{SF}$ in the animal model as we expected the ECM-SF to diffuse over time and wanted to maintain a sufficiently high concentration throughout the tumors to see an antiglioma effect. Only one timepoint was included in the in vitro experiment but this was followed with an in vivo experiment which tracked tumor volume for ten weeks. In a pre-study sample size calculation with continuous endpoints, two independent samples determined a minimum of $N=6$ for the control and treatment groups where $\alpha$ and $\beta$ were set to 0.05 and 0.8 respectively and control and treatment group means were $150 \mathrm{~mm}^{3}$ and 75 $\mathrm{mm}^{3}$ with a standard deviation of $45 \mathrm{~mm}^{3}$. Control volume mean was informed by the day 28 timepoint of a similar C6 glioma model, treatment mean was conservatively informed by in vitro studies, and standard deviation was set 
conservatively to allow for biologic variability [36]. Due to the unexpected result of half of the treatment animals succumbing to their tumor burden, biological variability was higher than anticipated, resulting in a significant difference between the survival curves being found by the Mantel-Cox method $(P=0.045)$ but not the GehanBreslow-Wilcoxon method (0.086). ECM is derived from a natural source and requires manual processing which results in sample variability. Multiple biological replicates were included in all stages of experimentation to gather representative data. Survival curves include animals that died directly from the glioma burden as well as animals that had to be sacrificed in accordance with IACUC tumor burden guidelines. As with all proteomic analyses the list of identified protein species is not comprehensive as the dark proteome could not be represented in the results.

Intervention with liquid fractions of non-neoplastic mammalian extracellular matrix (ECM) may lead to smaller tumor volume and increased lifespan in patients with glioblastoma multiforme. Further research into the anti-cancer effects of ECM biomaterials is warranted.

\section{MATERIALS AND METHODS}

\section{ECM-SF preparation}

Adult porcine bladders were acquired (Tissue Source, LLC, Lafayette, IN) and urinary bladder extracellular matrix (ECM) was isolated as previously described [17]. ECM sheets were then lyophilized for 72 hours, comminuted through a 40-mesh sieve in a Thomas Scientific Wiley Mini Mill, and tumbled in a Fisher Scientific tube revolver in normal saline at 10 $\mathrm{mg} / \mathrm{mL}$ for 24 hours at room temperature. ECM particles were pelleted via centrifugation at $100,000 \mathrm{rpm}$ for 30 minutes and supernatant was passed through 100 um cell strainers and then 0.22-micron sterile filters. Resulting liquid was concentrated 200 -fold by volume in $10 \mathrm{kDa}$ cutoff columns (MilliporeSigma UFC901008, Darmstadt, Germany) and protein concentration was approximated using a Nanodrop A280 measurement to verify cutoff column filter integrity. Samples were stored at $-20^{\circ} \mathrm{C}$ until use.

\section{Cell origin, culture, and viability assay}

Patient derived glioma cells (designated as 0319, $1015,1119)$ were used before passage 20. Glioma cell lines (A172, T98G, U87MG, and C6) and non-neoplastic CNS cells (HCN2 and HMC3) were obtained from ATCC (Manassas, Virginia). ATCC routinely utilizes short tandem repeat profiling to authenticate their cell line products. All cells were cultured in high-glucose DMEM with $10 \% \mathrm{FBS}$ and $1 \%$ pen/strep with incubation at $37^{\circ} \mathrm{C}$ in a $5 \% \mathrm{CO} 2$ environment. With exception to $\mathrm{HCN} 2$ cells which originated from a female, all cell lines used originated from male sources. Growth media was spiked with ECM-SF at concentrations of 1,5 , and $10 \mathrm{mg} / \mathrm{mL}$ for viability experiments which were conducted in triplicate. Cells were plated at 12,000/well in 96 well plates and allowed to attach overnight before spiked media was introduced. 24 hours later cell viability was measured with LIVE/DEAD ${ }^{\mathrm{TM}}$ Viability/Cytotoxicity Kit from Invitrogen (L3224 Waltham, Massachusetts), as per manufacturer's instructions, read with a Molecular Devices SpectraMax M2 and reported as ratio of dead signal to live signal normalized to media control.

\section{Time lapse videography with NucView 488 reagent}

125,000 cells of 0319,1119 , and HMC3 were plated into 12 -well plates and allowed to attach overnight. Wells were treated either with media spiked with $3 \mathrm{mg} / \mathrm{mL}$ ECM-SF and 1.5 uM NucView 488 Caspase-3 Reagent (Biotium), or media plus NucView 488 alone. Images were taken every 10 minutes for 12 hours and compiled in AxioVs40 (Carl Zeiss) to create time-lapse videos. Static data shown in graphical form is at the 12-hour timepoint.

\section{Animal experiments}

Animal experiments were performed in accordance with the regulations and approval of the Institutional Animal Care and Use Committee (IACUC) of the University of Pittsburgh. Animals used for the systemic intravenous injection study were opportunistically female. Male animals were used in the GBM model as malignant brain tumors generally occur more commonly in males [37].

\section{Systemic intravenous injection}

Adult female Sprague-Dawley rats from Envigo (Indianapolis, Indiana) 250-300 g in weight were used for the systemic intravenous injection study. Animals were randomly assigned into treatment or control groups $(N=5)$ and given either $120 \mathrm{mg} / \mathrm{kg}$ of ECM-SF or the equivalent volume in normal saline every other week for a total of five injections through the tail vein. One week prior to this and every other week afterward for a total of six times, $500 \mathrm{uL}$ of blood was drawn via saphenous vein puncture into EDTA coated Sarstedt Microvette tubes (Sarstedt Inc 20.1341.102, Numbrecht, Germany). Complete blood count was performed by Marshfield Labs (Marshfield, WI) and red blood cell count, red blood cell distribution, hemoglobin, and hematocrit are reported. Weight and temperature for each animal was monitored and recorded weekly. Rat temperature was monitored using a small rodent infrared thermometer from Braintree Scientific, Inc (IR-B153, Braintree, Massachusetts). 


\section{FITC-dextran spiked ECM-SF intracranial injection}

ECM-SF was spiked with $1 \mathrm{mg} / \mathrm{mL} 70 \mathrm{kda}$ FITCdextran (Sigma Aldrich 46945, Cleveland, Ohio). Adult male Wistar rats 250-300 g in weight $(N=4$, Charles River Laboratories) were anesthetized with ketamine/ xylazine (90/15 mg/kg intraperitoneal injection) and placed in a stereotaxic frame with $1-3 \%$ isoflurane and oxygen flowing from a nose cone. Skin was shaved and a $5 \mathrm{~mm}$ incision was made, allowing a burr hole to be drilled $2 \mathrm{~mm}$ lateral to the midline on the right side and $1 \mathrm{~mm}$ posterior to the bregma. A $500 \mathrm{uL}$ Hamilton syringe tipped with a 25-gauge needle and attached to a syringe pump (Harvard Apparatus PHD 2000, Holliston, Massachusetts) delivered FITC-dextran spiked ECM-SF at a rate of $1 \mathrm{uL} /$ minute for 10 minutes at a depth of $2 \mathrm{~mm}$ below the brain surface. After a 5-minute equilibration period the syringe was slowly removed, the skin was sutured and glued, and the animal was recovered. Two animals were sacrificed at 30 minutes post injection, and two were sacrificed at 24 hours post injection. Sacrifice was achieved by $\mathrm{CO} 2$ asphyxiation followed by cervical dislocation, and brains were immediately harvested and placed in $10 \%$ neutral buffered formalin. Slides were imaged with a Motic EasyScan Pro 6 slide scanner and images exported using QuPath 0.3.2.

\section{Intracranial glioma model}

Adult male Wistar rats 250-300 g in weight were used for the intracranial glioma model. Animals were randomly assigned into control or treatment groups ( $N=6$ each). C6 glioma cell suspensions at a density of $1 \times 10^{6}$ cells per $10 \mathrm{uL}$ in PBS were prepared fresh from mid-confluent cultures to maximize viability upon inoculation. C6 inoculum was administered via a stereotaxic frame and syringe pump as described above. At 7 days post operation and every week thereafter until day 70, animals were subjected to MRI. At days 7,14 , and 21 post inoculation animals received $10 \mathrm{uL}$ of either normal saline or $30 \mathrm{mg} / \mathrm{mL}$ ECM-SF at the same stereotaxic coordinates and flow rate as the tumor inoculation. At 70 days animals were sacrificed by $\mathrm{CO} 2$ asphyxiation and cervical dislocation.

\section{MRI analysis}

Rats were anesthetized via a nose cone with $1.5-2.5 \%$ isoflurane and $\mathrm{O} 2$. The rats were positioned on an animal bed with a stereotaxic head holder and placed in the scanner. A rectal temperature probe was used for monitoring and maintenance of temperature at $37.0 \pm 0.5^{\circ} \mathrm{C}$ using a warm air heating system. Respiration was monitored (SA Instruments, Stonybrook, New York).
MRI was performed using a 7T/30-cm AVIII spectrometer (Bruker Biospin, Billerica, Massachusetts) equipped with a $12 \mathrm{~cm}$ gradient set and using an $86 \mathrm{~mm}$ quadrature RF transmit volume coil, a 2-channel receive surface RF coil and Paravision 6.0.1. A T2-weighted RARE sequence was used to visualize the glioma in both axial and coronal orientations, with the following parameters (axial): repetition time $(\mathrm{TR}) /$ echo time $(\mathrm{TE})=5000 / 80 \mathrm{~ms}$, field of view $(\mathrm{FOV})=35 \times 35 \mathrm{~mm}$, acquisition matrix $=192 \times$ 192, 25 slices with a slice thickness of $1 \mathrm{~mm}, 2$ averages, and a RARE factor $=8$. The coronal images used the same parameters except 13 slices were used. Tumor volumes were calculated by manual segmentation in a blinded fashion using DSI Studio software (http://dsi-studio. labsolver.org/).

\section{Mass spectrometry}

Three biological replicates of lyophilized, comminuted native bladder, ECM, and liquid ECM-SF were prepared as described above. Protein was extracted from milled samples as previously described [38]. Briefly, bladder and ECM samples were homogenized with a bead beater in three rounds of a CHAPS/high salt buffer followed by successive extractions with guanidine- $\mathrm{HCl}$, and hydroxylamine-HCl. Approximately 30 ug of protein from each fraction and 30 ug of protein from ECM-SF was then trypsin digested using a filter-aided sample preparation (FASP) approach and C18 cleanup. Liquid chromatography tandem mass spectrometry (LC-MS/ MS) analysis was conducted as previously described [38]. Briefly, samples were analyzed in triplicate by a nanoUHPLC-MS/MS on an Easy-nLC1200 coupled with an orbitrap Fusion Lumos Tribrid (Thermo Fisher Scientific, Waltham, Massachusetts) mass spectrometer operating in positive ion mode. Approximately 3 ug of total protein was directly loaded onto an in-house packed 100 um i.d. $\times$ $250 \mathrm{~mm}$ fused silica column packed with CORTECS C18 resin $(2.7 \mathrm{um})$. Samples were run at $250 \mathrm{~nL} / \mathrm{min}$ over a 90 min linear gradient from $4-28 \%$ acetonitrile in $0.1 \%$ formic acid. MS data acquisition was identical to those previously described [38]. Protein identification and label free quantification was done with Proteome Discoverer Software package (v2.4). Database searching was done using Mascot (v2.5) with peptide spectral matches mapped against the Uniprot Sus Scrofa database. Mass tolerances were set to $+/-10 \mathrm{ppm}$ for parent ions, and $+/-25 \mathrm{ppm}$ for fragment ions. Mixed C-terminal N (hydroxylamine specificity) and trypsin were used as cleavage rules, allowing for 2 missed cleavages. Asn and Gln deamidation, Met oxidation, Pro hydroxylation, Gln to Pyro-Glu were set as variable modification with Cys carbamidomethylation set as a fixed modification. False discovery rates were calculated using Percolator with peptide and protein identifications requiring an FDR of less than 1\%. 


\section{Statistical analysis}

Data statistical analysis was performed using GraphPad Prism 7.03 software. Mantel-Haenszel approach for hazard ratio and confidence interval of Kaplan-Meier survival curve was reported. Both GehanBreslow-Wilcoxon and Mantel-Cox methods were used for comparison of survival curves. Student's $t$-test was used to compare groups of two. One-way ANOVA and Tukey's honest significant difference were used to find differences in groups of more than two. $P$-values lower than 0.05 were considered significant. Appropriate numerical data are shown as mean \pm standard deviation. Heat maps plotted protein species relative abundance along -2- to 2-fold change. Volcano plots used cutoff criteria of $P=0.1$ and increased presence by at least a 2-fold ratio.

\section{Author contributions}

\begin{abstract}
Mark H. Murdock: Conceptualization, Methodology, Validation, Formal analysis, Investigation, Data acquisition, Data curation, Writing, Visualization, Funding acquisition. George S. Hussey: Conceptualization, Formal analysis, Investigation, Writing, Supervision. Jordan T. Chang: Methodology, Validation, Data curation. Ryan C. Hill: Methodology, Validation, Formal analysis, Investigation, Resources, Data acquisition, Data curation, Visualization. David G. Nascari: Validation, Data acquisition, Data curation. Aparna V. Rao: Methodology, Validation, Data curation, Material acquisition. Kirk C. Hansen: Methodology, Validation, Formal analysis, Investigation, Resources, Data acquisition, Data curation, Visualization. Lesley M. Foley: Methodology, Validation, Resources, Data acquisition, Data curation, Visualization. T. Kevin Hitchens: Methodology, Validation, Resources, Data acquisition, Data curation, Visualization. Nduka M. Amankulor: Methodology, Validation, Formal analysis, Data curation, Material acquisition, Writing, Visualization. Stephen F. Badylak: Conceptualization, Methodology, Formal analysis, Investigation, Data curation, Writing, Visualization, Supervision, Project administration, Funding acquisition.
\end{abstract}

\section{ACKNOWLEDGMENTS}

We are grateful for the method development assistance of Aimon Iftikhar regarding the intracranial model, the technical assistance of Lori Walton for histology, the imaging assistance of Kelsey Hall, the IACUC and drug/chemical expertise of Scott Johnson, the DLAR personnel at the Hillman Cancer Center, and the DLAR personnel at the Bridgeside Point II animal facility.

\section{CONFLICTS OF INTEREST}

S.F.B and G.S.H. have a vested interest in ECM Therapeutics which is pursuing intellectual property related to the materials used in the study. All other authors have no competing interests to declare.

\section{FUNDING}

Research reported in this publication was supported by the National Center for Advancing Translational Sciences of the National Institutes of Health (NIH) under Award Number TL1TR001858 (MHM). The content is solely the responsibility of the authors and does not necessarily represent the official views of the NIH. Additional support for this work was provided by sponsored research agreements from CR Bard/ Becton Dickinson, ECM Therapeutics, Inc, and the Commonwealth of Pennsylvania. This project also used the resources of the UPMC Hillman Cancer Center In Vivo Imaging Facility that is supported in part by NIH award P30-CA-047904.

\section{REFERENCES}

1. Rilla K, Mustonen AM, Arasu UT, Härkönen K, Matilainen $\mathrm{J}$, Nieminen P. Extracellular vesicles are integral and functional components of the extracellular matrix. Matrix Biol. 2019; 75-76:201-19. https://doi.org/10.1016/j. matbio.2017.10.003. [PubMed]

2. Bosman FT, Stamenkovic I. Functional structure and composition of the extracellular matrix. J Pathol. 2003; 200:423-28. https://doi.org/10.1002/path.1437. [PubMed]

3. Huleihel L, Hussey GS, Naranjo JD, Zhang L, Dziki JL, Turner NJ, Stolz DB, Badylak SF. Matrix-bound nanovesicles within ECM bioscaffolds. Sci Adv. 2016; 2:e1600502. https:// doi.org/10.1126/sciadv.1600502. [PubMed]

4. Bissell MJ, Hall HG, Parry G. How does the extracellular matrix direct gene expression? J Theor Biol. 1982; 99:31-68. https://doi.org/10.1016/0022-5193(82)90388-5. [PubMed]

5. Bornstein P, McPherson J, Sage H. Synthesis and secretion of structural macromolecules by endothelial cells in culture. In: Nossel HL, Vogel HJ, ed. Pathobiology of the Endothelial Cell. New York: Academic Press; 1982. pp. 215-28. https:// doi.org/10.1016/B978-0-12-521980-8.50020-1.

6. Soto AM, Sonnenschein C. Emergentism as a default: cancer as a problem of tissue organization. J Biosci. 2005; 30:103-18. https://doi.org/10.1007/BF02705155. [PubMed]

7. Soto AM, Sonnenschein C. The tissue organization field theory of cancer: a testable replacement for the somatic mutation theory. Bioessays. 2011; 33:332-40. https://doi. org/10.1002/bies.201100025. [PubMed]

8. Bissell MJ, Radisky DC, Rizki A, Weaver VM, Petersen OW. The organizing principle: microenvironmental influences in the normal and malignant breast. 
Differentiation. 2002; 70:537-46. https://doi.org/10.1046/ j.1432-0436.2002.700907.x. [PubMed]

9. Hodde JP, Suckow MA, Wolter WR, Hiles MC. Small intestinal submucosa does not promote PAIII tumor growth in Lobund-Wistar rats. J Surg Res. 2004; 120:189-94. https://doi.org/10.1016/i.jss.2003.10.022. [PubMed]

10. Hurst RE, Hauser PJ, Kyker KD, Heinlen JE, Hodde JP, Hiles MC, Kosanke SD, Dozmorov M, Ihnat MA. Suppression and activation of the malignant phenotype by extracellular matrix in xenograft models of bladder cancer: a model for tumor cell "dormancy". PLoS One. 2013; 8:e64181. https://doi.org/10.1371/journal.pone.0064181. [PubMed]

11. Hurst RE, Kyker KD, Bonner RB, Bowditch RD, Hemstreet GP 3rd. Matrix-dependent plasticity of the malignant phenotype of bladder cancer cells. Anticancer Res. 2003; 23:3119-28. [PubMed]

12. Badylak SF, Hoppo T, Nieponice A, Gilbert TW, Davison JM, Jobe BA. Esophageal preservation in five male patients after endoscopic inner-layer circumferential resection in the setting of superficial cancer: a regenerative medicine approach with a biologic scaffold. Tissue Eng Part A. 2011; 17:1643-50. https://doi.org/10.1089/ten.TEA.2010.0739. [PubMed]

13. Saldin LT, Patel S, Zhang L, Huleihel L, Hussey GS, Nascari DG, Quijano LM, Li X, Raghu D, Bajwa AK, Smith NG, Chung CC, Omstead AN, et al. Extracellular Matrix Degradation Products Downregulate Neoplastic Esophageal Cell Phenotype. Tissue Eng Part A. 2019; 25:487-98. https://doi.org/10.1089/ten.TEA.2018.0105. [PubMed]

14. Wolf MT, Ganguly S, Wang TL, Anderson CW, Sadtler K, Narain R, Cherry C, Parrillo AJ, Park BV, Wang G, Pan F, Sukumar S, Pardoll DM, Elisseeff JH. A biologic scaffoldassociated type 2 immune microenvironment inhibits tumor formation and synergizes with checkpoint immunotherapy. Sci Transl Med. 2019; 11:eaat7973. https://doi.org/10.1126/ scitranslmed.aat7973. [PubMed]

15. Saldin LT, Klimak M, Hill RC, Cramer MC, Huleihel L, Li X, Quidgley-Martin M, Cardenas D, Keane TJ, Londono R, Hussey G, Kelly L, Kosovec JE, et al. The effect of normal, metaplastic, and neoplastic esophageal extracellular matrix upon macrophage activation. J Immunol Regen Med. 2021; 13:100037. https://doi.org/10.1016/j.regen.2020.100037. [PubMed]

16. Naranjo JD, Saldin LT, Sobieski E, Quijano LM, Hill RC, Chan PG, Torres C, Dziki JL, Cramer MC, Lee YC, Das R, Bajwa AK, Nossair R, et al. Esophageal extracellular matrix hydrogel mitigates metaplastic change in a dog model of Barrett's esophagus. Sci Adv. 2020; 6:eaba4526. https://doi. org/10.1126/sciadv.aba4526. [PubMed]

17. Freytes DO, Martin J, Velankar SS, Lee AS, Badylak SF. Preparation and rheological characterization of a gel form of the porcine urinary bladder matrix. Biomaterials. 2008; 29:1630-37. https://doi.org/10.1016/j. biomaterials.2007.12.014. [PubMed]
18. Slivka PF, Dearth CL, Keane TJ, Meng FW, Medberry CJ, Riggio RT, Reing JE, Badylak SF. Fractionation of an ECM hydrogel into structural and soluble components reveals distinctive roles in regulating macrophage behavior. Biomater Sci. 2014; 2:1521-34. https://doi.org/10.1039/ c4bm00189c. [PubMed]

19. Ghuman H, Massensini AR, Donnelly J, Kim SM, Medberry CJ, Badylak SF, Modo M. ECM hydrogel for the treatment of stroke: Characterization of the host cell infiltrate. Biomaterials. 2016; 91:166-81. https://doi.org/10.1016/j. biomaterials.2016.03.014. [PubMed]

20. Huleihel L, Dziki JL, Bartolacci JG, Rausch T, Scarritt ME, Cramer MC, Vorobyov T, LoPresti ST, Swineheart IT, White LJ, Brown BN, Badylak SF. Macrophage phenotype in response to ECM bioscaffolds. Semin Immunol. 2017; 29:213. https://doi.org/10.1016/j.smim.2017.04.004. [PubMed]

21. Reing JE, Zhang L, Myers-Irvin J, Cordero KE, Freytes DO, Heber-Katz E, Bedelbaeva K, McIntosh D, Dewilde A, Braunhut SJ, Badylak SF. Degradation products of extracellular matrix affect cell migration and proliferation. Tissue Eng Part A. 2009; 15:605-14. https://doi. org/10.1089/ten.tea.2007.0425. [PubMed]

22. Delgado LM, Bayon Y, Pandit A, Zeugolis DI. To crosslink or not to cross-link? Cross-linking associated foreign body response of collagen-based devices. Tissue Eng Part B Rev. 2015; 21:298-313. https://doi.org/10.1089/ten. TEB.2014.0290. [PubMed]

23. Bible E, Dell'Acqua F, Solanky B, Balducci A, Crapo PM, Badylak SF, Ahrens ET, Modo M. Non-invasive imaging of transplanted human neural stem cells and ECM scaffold remodeling in the stroke-damaged rat brain by (19)F- and diffusion-MRI. Biomaterials. 2012; 33:2858-71. https://doi. org/10.1016/j.biomaterials.2011.12.033. [PubMed]

24. Ghuman H, Gerwig M, Nicholls FJ, Liu JR, Donnelly J, Badylak SF, Modo M. Long-term retention of ECM hydrogel after implantation into a sub-acute stroke cavity reduces lesion volume. Acta Biomater. 2017; 63:50-63. https://doi.org/10.1016/j.actbio.2017.09.011. [PubMed]

25. Ghuman H, Mauney C, Donnelly J, Massensini AR, Badylak SF, Modo M. Biodegradation of ECM hydrogel promotes endogenous brain tissue restoration in a rat model of stroke. Acta Biomater. 2018; 80:66-84. https://doi. org/10.1016/j.actbio.2018.09.020. [PubMed]

26. Faust A, Kandakatla A, van der Merwe Y, Ren T, Huleihel L, Hussey G, Naranjo JD, Johnson S, Badylak S, Steketee M. Urinary bladder extracellular matrix hydrogels and matrix-bound vesicles differentially regulate central nervous system neuron viability and axon growth and branching. J Biomater Appl. 2017; 31:1277-95. https://doi. org/10.1177/0885328217698062. [PubMed]

27. van der Merwe Y, Faust AE, Sakalli ET, Westrick CC, Hussey G, Chan KC, Conner IP, Fu VLN, Badylak SF, Steketee MB. Author Correction: Matrix-bound nanovesicles prevent ischemia-induced retinal ganglion cell axon degeneration and death and preserve visual function. 
Sci Rep. 2019; 9:15799. https://doi.org/10.1038/s41598019-50829-2. [PubMed]

28. MacEwan MR, Kovacs T, Osbun J, Ray WZ. Comparative analysis of a fully-synthetic nanofabricated dura substitute and bovine collagen dura substitute in a large animal model of dural repair. Interdisciplinary Neurosurgery. 2018; 13:145-50. https://doi.org/10.1016/j.inat.2018.05.001.

29. Pencheva N, de Gooijer MC, Vis DJ, Wessels LFA, Würdinger T, van Tellingen O, Bernards R. Identification of a Druggable Pathway Controlling Glioblastoma Invasiveness. Cell Rep. 2017; 20:48-60. https://doi. org/10.1016/i.celrep.2017.06.036. [PubMed]

30. Sheng XD, Chen H, Wang H, Ding ZB, Xu GZ, Zhang JF, $\mathrm{Lu}$ WC, Wu T, Zhao L. Fibulin-5 is a prognostic marker that contributes to proliferation and invasion of human glioma cells. Asian Pac J Cancer Prev. 2015; 16:769-73. https://doi. org/10.7314/apjep.2015.16.2.769. [PubMed]

31. Guo SK, Shen MF, Yao HW, Liu YS. Enhanced Expression of TGFBI Promotes the Proliferation and Migration of Glioma Cells. Cell Physiol Biochem. 2018; 49:1097-109. https://doi.org/10.1159/000493293. [PubMed]

32. Shen M, Jiang YZ, Wei Y, Ell B, Sheng X, Esposito M, Kang J, Hang X, Zheng H, Rowicki M, Zhang L, Shih WJ, Celià-Terrassa $T$, et al. Tinagl1 Suppresses TripleNegative Breast Cancer Progression and Metastasis by Simultaneously Inhibiting Integrin/FAK and EGFR Signaling. Cancer Cell. 2019; 35:64-80.e7. https://doi. org/10.1016/j.ccell.2018.11.016. [PubMed]

33. Chen Y, Song Y, Du W, Gong L, Chang H, Zou Z. Tumorassociated macrophages: an accomplice in solid tumor progression. J Biomed Sci. 2019; 26:78. https://doi. org/10.1186/s12929-019-0568-z. [PubMed]

34. Boatright KM, Salvesen GS. Mechanisms of caspase activation. Curr Opin Cell Biol. 2003; 15:725-31. https:// doi.org/10.1016/j.ceb.2003.10.009. [PubMed]
35. Massensini AR, Ghuman H, Saldin LT, Medberry CJ, Keane TJ, Nicholls FJ, Velankar SS, Badylak SF, Modo M. Concentration-dependent rheological properties of ECM hydrogel for intracerebral delivery to a stroke cavity. Acta Biomater. 2015; 27:116-30. https://doi.org/10.1016/j. actbio.2015.08.040. [ [PubMed]

36. Souza TKF, Nucci MP, Mamani JB, da Silva HR, Fantacini DMC, de Souza LEB, Picanço-Castro V, Covas DT, Vidoto EL, Tannús A, Gamarra LF. Image and motor behavior for monitoring tumor growth in C6 glioma model. PLoS One. 2018; 13:e0201453. https://doi.org/10.1371/journal. pone.0201453. [PubMed]

37. Yang W, Warrington NM, Taylor SJ, Whitmire P, Carrasco E, Singleton KW, Wu N, Lathia JD, Berens ME, Kim AH, Barnholtz-Sloan JS, Swanson KR, Luo J, Rubin JB. Sex differences in GBM revealed by analysis of patient imaging, transcriptome, and survival data. Sci Transl Med. 2019; 11:eaao5253. https://doi.org/10.1126/scitranslmed.aao5253. [PubMed]

38. Schmitt LR, Henderson R, Barrett A, Darula Z, Issaian A, D'Alessandro A, Clendenen N, Hansen KC. Mass spectrometry-based molecular mapping of native FXIIIa cross-links in insoluble fibrin clots. J Biol Chem. 2019; 294:8773-78. https://doi.org/10.1074/jbc.AC119.007981. [PubMed] 